\title{
Intravascular fibrinolysis in treating the thromboembolic changes in lower limbs
}

\author{
Dawid Siemieniuk', Tadeusz Mularczyk', Waldemar Kostewicz ${ }^{1,2}$ \\ 'Department of General and Vascular Surgery, Międzylesie Specialist Hospital in Warsaw, Poland \\ ${ }^{2}$ Department and Clinic of General and Vascular Surgery of the Second Faculty of Medicine, \\ Medical University of Warsaw, Poland
}

\begin{abstract}
Introduction. One of the methods of treating the limbs ischaemia is local intravascular fibrinolysis. The aim of using this method is fast restoration of arteries patency what enables blood flow to the ischaemic limb and allows to diagnose the cause of the occlusion of arteries or a vascular bypass. Identification and determination of the changes type in the arterial wall allows to plan further treatment using surgical and endovascular methods.

Material and methods. During 2003-20 I 4, 4 I patients were treated using the method of local fibrinolysis. In all of the cases the occlusion occurred in the femoropopliteal section. All of the patients had the colour Doppler echocardiography carried out, and then angiography, to confirm the diagnosis. The catheter was inserted through a puncture in the common femoral artery. The catheter tip was placed above the arterial thrombus. In 2003-2005 streptokinase was used as the fibrinolytic drug. Then, in 2005-20 I 4 the usage of rtPA (alteplase) had been started. The progress of thrombolysis was monitored by repeated angiography. The fibrinolytic treatment had been continued for 6 more hours from obtaining the vessel patency confirmed by radiology.

Results. In 15 patients (88\%) in 2003-2005 (group in which streptokinase was used) and 21 patients (87.5\%) in 2005-2014 (group in which alteplase was used) patency of the initially clotted artery and full remission of the ischaemic limb symptoms was obtained. In 4 cases the intravascular thrombolysis ended with failure. Simultaneously, embolectomy with Fogarty's catheter was carried out. In the group treated with rtPA two deaths were noted: due to acute coronary syndrome and hypertensive crisis.

Conclusions. Local intravascular fibrinolysis is a good and effective method of treatment of the limbs ischaemia in certain patients. It allows to lower the dosages of the thrombolytic drugs and can be a good alternative for the surgical treatment.
\end{abstract}

Key words: arterial thrombosis, vascular bypass thrombosis, intravascular fibrinolysis, alteplase

Acta Angiol 2015; $21,1:$ I-7

\section{Introduction}

Today, local intravascular fibrinolysis is one of recognised and little invasive techniques of endovascularization. It was used and described for the first time by Dotter in 1974 [I]. For 40 years the fibrinolytic factor and techniques of its administration has been gradually improved. It is an alternative for the surgical restoration of patency of own artery or vascular bypass, giving in certain groups of patients higher benefits than surgery. Surgical treatment of acute arterial ischaemia of lower limbs has a 30-day mortality index from $15 \%$ to $25 \%$ due to complications. Intravascular fibrinolysis is a well-tolerated and often used method that can offer 
few potential advantages in comparison to surgical treatment [2].

The significance of the thrombolytic treatment has been proven in numerous retrospective trials and in carefully designed prospective trials in which individual fibrinolytic drugs, their different dosages and the results of fibrinolytic treatment and the results of surgical treatments were compared. Skipping the detailed analysis of the results of the above-mentioned mentioned trials, citation of which exceeds the range of this report, the following studies need to be mentioned: STILE, TOPAS, PURPOSE, and PARES [3-15].

Applying the targeted thrombolysis in treating the arterial and vascular bypass thrombosis can be a beneficial alternative for the surgical treatment (in the STILE study [II] this thesis was confirmed) and for thrombolysis with intravenous infusion of the drug. This approach also allows to avoid flaws connected to both these methods. Administration of the fibrinolytic drug in the direct vicinity or directly into the thrombus allows to lower the drug dosage by many times in comparison to dosages used in intravenous infusion of the drug, despite the used technique of thrombolysis and to shorten the treatment duration. The thrombolytic drug dosage size is directly connected with the risk of general lytic state and haemorrhagic complications [7, 16-19].

The method of restoring arteries patency using the balloon catheter proposed by Fogarty in the 1960s $[20,21]$ resulted in improvement of the techniques of thrombectomy and embolectomy. Despite this, in next years of the observations the attention was drawn also to the disadvantages of this method. Due to the thrombotic changes in the peripheral vessels caused by the thrombus, the method can fail to bring the anticipated result even with successful restoring patency in the main anatomical stem. Furthermore, it can result in damage of the endomembrane and provoke development of another thrombus in that place. Mechanical deformation of the wall and multiple passage of the catheter with an expanded balloon can also be the cause of secondary extensive stenoses or hyperplastic changes in the vessel's wall (myointimal hyperplasia) [22-24].

Berridge, Kessel and Robertson et al. analysed five controlled trials with 1283 patients that were randomly allocated to groups in which peripheral intravascular thrombolysis or surgical treatment were used due to acute arterial ischaemia of lower limbs. The results, however, did not give unambiguous evidences that the intravascular thrombolysis or surgical treatment is the preferred option in order to avoid amputation of the limb or to lower the risk of death in the first year [26]. However, local intravascular thrombolysis gave more benefits when taking into consideration the costs of treatment, duration of hospitalisation and absence, and comfort subjectively experienced by the patient in comparison to surgical treatment [25].

The aim of the study was an evaluation of the effectiveness of the thrombosis of peripheral arteries treatment using local intravascular fibrinolysis.

\section{Material and methods}

In 2003-20 I 4, 4 I patients with occlusion of lower limb arteries in the femoropopliteal section were treated with local intravascular fibrinolysis. In 2003-2005 the studied group comprised of 12 (71\%) men and 5 (29\%) women; the average age: 53 years old; the age range: 44-75 years. In 2005-2014 the studied group comprised of $19(79 \%)$ men and 5 (21\%) women, the average age: 60 years old; the age range: $42-78$ years. In all cases the occlusion of lower limbs arteries concerned the femoropopliteal section. The clinical picture of the ischaemia comprised of considerable and sudden shortened claudication distance, subjective feeling of cold, numbness of resting foot and paleness of skin and suppressed filling-in of the surface veins. In one patient the thrombosis occurred $12 \mathrm{~h}$ after angioplasty and stenting the surface femoral artery. Three patients were diagnosed with chronic ischaemia of lower limbs in stadium Ilb according to the Fontaine's classification and one female patient had no symptoms of lower limbs ischaemia in the period preceding the occurrence of the arterial thrombus. The risk factors of developing sclerosis occurring in the observed group were: habitual smoking (30 patients), hypertension (18 patients), obesity ( 7 patients), insulin-dependent diabetes (4 patients), and kidney failure (3 patients).

All of the patients had the colour Doppler echocardiography of the arterial flow carried out, and then abstract angiography, thanks to which the diagnosis had been confirmed. To perform the intravascular thrombolysis, 2 types of catheter were used: with one axially located hole in 5 cases and with numerous holes laterally located in 36 cases. The catheter was inserted through the cannula with a valve into the puncture of the common femoral artery on the opposite side. The tip of the catheter was placed peripherally, just under the surface or inside the mass of thrombus.

In 2003-2014 all of the patients received subcutaneous injection of nadroparin in a dosage of $0.01 \mathrm{~mL} / \mathrm{kg}$ of body weight or fraxiparine in a dosage of $\mathrm{I} \mathrm{mg} / \mathrm{kg}$ of body weight and then streptokinase (SK) or recombined tissue plasminogen activator - alteplase (rtPA). Both drugs were administered directly through the arterial line, SK in bolus intra-arterially in a dosage of $50000 \mathrm{IU}$ during $30 \mathrm{~min}$, and then constant-rate infusion intra-arterially in a dosage of $10000 \mathrm{IU} / \mathrm{h}$, rtPA in bolus intra-arterially in a dosage of $2 \mathrm{mg}$ and 
then constant-rate infusion intra-arterially in a dosage of $0.8 \mathrm{mg} / \mathrm{h}$. The effectiveness of the thrombolysis was monitored by arteriography carried out in I h since the administration of thrombolytic drugs, and then after $3 \mathrm{~h}$ and $6 \mathrm{~h}$ of treatment. In the group in which the rtPA was used, unfractionated heparin was administered in constant-rate infusion intra-arterially in a dosage of $200 \mathrm{IU} / \mathrm{h}$ during 48-72 $\mathrm{h}$ after the end of the infusion of the thrombolytic drug. In the group, in which SK was used, after restoring full patency of artery confirmed by angiography, the infusion of thrombolytic was continued for the next $6 \mathrm{~h}$. During next $48 \mathrm{~h}$ unfractionated heparin was administered in constant-rate intravenous infusion in a dosage allowing 2-3 times increase of the activated partial thromboplastin time, and then nadroparin in daily subcutaneous dosage of $0.02 \mathrm{~mL} / \mathrm{kg}$ of body weight, fraxiparine in daily subcutaneous dosage of $1 \mathrm{mg} / \mathrm{kg}$ of body weight or oral anticoagulant in therapeutic dosage under the control of the INR index. The total treatment time with SK and rtPA was from 12 to $36 \mathrm{~h}$. Patients were discharged from the unit in 2 or 3 day after termination of the intravenous treatment with heparin with recommendation to continue the subcutaneous injections of nadroparin/fraxiparine or oral anticoagulant under the control of the INR index.

\section{Results}

Dissolving the thrombus and restoring the arterial flow was reached in 15 (88\%) from 17 patients in 2003-2005 (study group treated with SK) and 21 (87.5\%) from 24 patients (group treated with rtPA). In 4 cases the local thrombolysis failed and the arterial flow was restored with the Fogarty's catheter. In the study group treated with rtPA two cases of death were noted due to acute coronary syndrome and hypertensive crisis. Among other patients no haemorrhagic complications or deterioration of the blood flow in the treated limbs requiring conversion to surgical treatment were found. In the group of 7 patients periarterial haematomas in the pace of cannulation of the artery that did not require surgical intervention were noted. In a patient with a thrombus in the stent inserted 2 weeks earlier, after restoring patency of the artery, no changes requiring additional intravascular surgeries were found. In 8 cases serious hemodynamic stenosis was diagnosed and simultaneously transcutaneous angioplasty with stenting of the narrowed section was carried out. Those patients were administered nadroparin/fraxiparine for 10 days, and then antiplatelet drugs. One female patient who was diagnosed with $40 \%$ stenosis of popliteal artery did not express consent to proposed angioplasty and stenting. After the end of injections of the nadroparin she started to use oral anticoagulants. In all of the treat- ed patients full remission of limb ischaemia symptoms was observed.

\section{Discussion}

The mechanism of action of the thrombolytic drugs relies on dissolving the fibre contributing to the thrombus by activating the inactive plasminogen connected with the fibre and creation of the plasmin. Currently, 4 basic substances showing fibrinolytic activity are being used, however, the use of rtPA predominates:

- streptokinase (SK) - a substance produced by the beta-hemolytic streptococci; SK binds with the circulating fibrinogen in an active complex that causes transformation of free plasminogen into a plasmin. In patients who suffered streptococcal infection or were previously treated with the streptokinase, antibodies can be created responsible for the occurrence of the anaphylactic reaction or neutralising the streptokinase therapeutical action;

- urokinase (UK) - serine protease; it is produced from the foetal kidney cells through genetic recombination. Its fibrinolytic activity comprises of direct transformation of the plasminogen to plasmin. It is considered a faster and more effective drug than streptokinase, and its antigenic properties are very low;

- tissue plasminogen activator (tPA) - is produced by the vascular endothelium or in laboratory, through the genetic recombination. When created in natural conditions in the wall of the vessel it results in normal endothelium having no thrombogenic properties. In comparison to streptokinase and urokinase tPA has significantly higher affinity and specificity to fibrin and this result in significantly lower risk of generalised haemorrhagic complications.

Other drugs, such as: reteplase (rPA), recombinant urokinase (rUK), recombinant prourokinase ( $r$-ProUK), recombinant staphylokinase, APSAC are still in the stage of clinical trials and are not used in treatments or their practical importance is still low $[27,28]$. Plasmin is a substance that has direct thrombolytic effect with extended safety margin shown in the preclinical trials. In these trials it was shown that when administering the plasmin through intravascular catheter we receive effective thrombolysis without adverse symptoms that can be observed using the rtPA. The safety of using the plasmin is a result of its fast neutralisation with the alpha 2-antiplasmin that prevents filtering of the plasmin to the circulatory system after the end of local thrombolysis. Further studies should evaluate the safety of using the plasmin in comparison to rtPA [29-32].

The results of the therapy are by far dependent on the qualification of patients to targeted thrombolysis. Commonly recognised indications to fibrinolytic treat- 
ments are: acute arterial thrombosis, acute vascular bypass thrombosis, chronic artery or vascular bypass occlusion lasting no longer than 14 days. Braithwaite et al. [33] consider that patients with the symptoms lasting no longer than 14 days should be qualified to surgical treatment. However, if this procedure would be contraindicated the attempt of performing thrombolysis can be taken. The results of the therapy in this group are significantly lower.

Absolute contraindications to thrombolysis are: active bleeding, active stomach and duodenum ulcers, stroke $<3$ months, surgery or biopsy of parenchymatous organ $<2$ weeks, cerebral vascular event $<6$ weeks, metastasis to the central nervous system, and lumbar puncture or spinal anaesthesia $<3$ days. Relative contraindications: suffered bleeding from the alimentary tract, surgery, biopsy or extensive injury during 10 preceding days, improperly controlled and high hypertension, presence of thrombus in the heart cavities, pregnancy, impairments of coagulation, acute liver failure and portal hypertension. Some authors suggest that special caution needs to be taken when qualifying the patients with engrafted vascular prosthesis, especially in the retroperitoneal space due to the possibility of causing a leakage. This observation concerns knitted dacron prostheses as well as the PTFE prostheses [33-35]. Usage of the streptokinase in the past is a contraindication for its second usage. This does not concern other thrombolytic drugs. Relative contraindications were vaguely determined. The attempts of treating patients with the necrosis of distal end of limb odd to be considered pointless and depreciative of the method, however, in some patients this procedure might allow to lower the level of amputation and to create better conditions for healing the stump wound. The decision on performing the therapy has to be individualised, and anticipated benefits has to significantly exceed the potential and conscious risk.

The final decision on starting the thrombolytic treatment has to be at all times preceded by diagnostic arteriography with careful exposure of the blocked part of the vessel and the vessels located above and below its location. This has crucial meaning to monitor the progress of the thrombolysis, and when the necessity of changing the treatment occurs, to precisely plan the surgical procedure.

Several techniques of intra-arterially administration of the thrombolytic drugs have been developed. None of them have become the obligatory standard procedure. In his pioneer report on the new method, Dotter [I] presented results obtained on the group of 17 patients, heterogeneous in regards to indications to thrombolysis and to used dosage and the way of its administration. This group consisted of patients with primary thrombosis of own artery, secondary thrombosis complicating the intravascular operations, vein thrombosis associated to the artery thrombosis, arterial embolism. The observation included patients not only with the atherosclerosis but also with the Raynaud's disease and embolism caused by the injection of a drug. The duration of symptoms was diverse, from a few minutes to 4 weeks and more. Dotter applied streptokinase to patients in constant-rate infusion through catheter with one hole or with several side openings, placed above the thrombus or introduced into the thrombus mass. The size of dosage was 2500-10 000 units per hour.

In 1989 Berridge et al. [17] performed a number of reviews of results of 19 prospective trials carried out in 1974-1988, in which intra-arterial thrombolysis was performed using small dosages of streptokinase (usually 5000 units/h) or rtPA administered in constant-rate infusion. In the conclusions, authors confirmed the therapeutic effectiveness of small dosages of locally administered thrombolytics in comparison to using high dosages that are used in the case of intravenous administration of the drug with time lower incidence of strokes and haemorrhagic complications at the same. Risius et al. [14] compared using two dosages of rtPA in the constant-rate infusion intra-arterially. Applying a dosage of $0.1 \mathrm{mg} / \mathrm{kg} / \mathrm{h}$ and $0.05 \mathrm{mg} / \mathrm{kg} / \mathrm{h}$ in two groups, respectively, identical effectiveness of the treatment was obtained with significantly lower incidence of haemorrhagic complications in the group of patients treated with the lower dosage.

The differences in various techniques of thrombolysis concerns the used catheter type, their number and placement in relation to the thrombus. In 1992 Hicks [36] performed a review of available systems for intra-arterial infusions and shown their clinical applications. Catheters with one apical hole or with multiple-hole tip are used. Two catheters placed coaxially are used. The tip of the catheter can be placed just above the thrombus or in the thrombus in its whole length or it can be moved along with the progress of the thrombolysis. The infusion of the drug can be with constant rate, preceded by initial bolus or can carried out as individual injections or by pulse-spray injections into the thrombus (pulse-spray pharmacomechanical thrombolysis).

McNamara and Fisher [12] treated patients with high dosages of urokinase in constant-rate infusion through catheter placed in the thrombus, firstly at 4000 units/min and after obtaining partial patency 2000 or 1000 units $/ \mathrm{min}$. Similar dosage in constant-rate infusion was used by Sullivan et al. [16] but it was preceded by additional infusion of bolus administered directly to the thrombus. The results were compared in two groups 
of patients. In one bolus in low dosage 7000-100 000 units (on average 52000 units); and in the second one in high dosage $120000-250000$ units (on average, 230000 units) was used. The conclusions in both researches were similar. The authors concluded that administering high dosages of thrombolytic decreases the duration of the thrombus lysis and lowers the total dosage of drug necessary to achieve that, and lowers the incidence of complications.

On the other hand, Conrad et al. [42] suggested re-surgery with implantation of a new vascular bypass instead of applying local thrombolysis among patients with the vascular graft thrombosis due to bad short-term results of the treatment.

Marder et al. [43], in phase I of the trial, administered increasing dosages of plasmin $(25-175 \mathrm{mg}$ ) in a group of 83 patients with acute (below 14 days) ischaemia of own arteries or vascular graft of lower limbs (scale of symptoms I or Ila). He concluded that using plasmin in the above-mentioned cases has good safety margin and tolerance for dosages $25-175 \mathrm{mg}$ administered locally through the intra-arterial catheter. The phase Il of the trial studies on the safety of applying, and indications to administration of plasmin in dosage of $150 \mathrm{mg}$ are being developed [44].

The differences in the approach to the thrombolytic treatments consider not only the used catheter type and its placement, and dosages of drugs but also the method of infusion. In the prospective randomised trial, Kandarpa et al. [9] compared the results of treatment with constant-rate infusion with individual injections of pulse-spray type. They did not show significant differences between groups in the evaluation of the therapy's effectiveness, the time needed to obtain lysis of the thrombus, incidence of complications, and results after 30-day observation. Valji et al., Bookstein et al., and Gardiner et al. [37-4I] consider the pulse-spray injections technique to be the most effective. The manipulation with the catheter tip within the thrombus and its mechanical breakage with the force of the injected stream results in shortening the duration of the treatment and lowers the total dosage of used drug, and in lowering the incidence of complications. Wissgott et al. [45] performed the PARes study to evaluate the safety of applying the local thrombolysis using ultrasounds in treating acute thrombosis or embolism of arteries in lower limbs. In the study, acute ischaemia (below 14 days) was treated applying local thrombolysis with rtPA in a dosage of $1.0 \mathrm{mg} / \mathrm{h}$ using special EKOS catheter for local thrombolysis with the ultrasonic device. The effectiveness index was $100 \%$. Full removing of the thrombus was noted in a group of 22 patients (88\%) after about 16.9 hours (range 5-24 h) using on average $17 \mathrm{mg}$ (range 5-25 mg) of rtPA. In the results of the studies it was concluded that using the EKOS catheter for local thrombolysis is efficient and effective.

With the intra-arterial infusion of the fibrinolytic drug, intravenous administration of heparin is recommended to avoid the appearance of new thrombus in the vicinity of the catheter. The dosages are very variable. Kandarpa [46], Sullivan et al. [16], and McNamara et al. [12] suggest full therapeutic heparinization using intravenous heparin bolus of 5000-7000 units, and then constant-rate infusion at 1000-2000 units/h. Valji and Bookstein et al. [37, 40] administered heparin according to the above plan or made a solution for intra-arterial infusion containing $10 \mathrm{~mL}$ of volume 250000 units of urokinase and 5000 units of heparin with simultaneous start of oral antiplatelet treatment. Other authors, e.g. Ouriel $[19,28]$, suggested to administer heparin in sub-therapeutic dosages: bolus 2000 units, and then infusion 200-500 units/h, while others, such as Braithwaite et al. [27], did not administer heparin to their patients during the thrombolysis but only during next $48 \mathrm{~h}$ from ending it, administering dosages allowing 2-3 times increase of activated partial thromboplastin time (APTT).

The decision on terminating the treatment is made when: the thrombus is completely dissolved, significant haemorrhagic complications occur, the state of the limb is deteriorating and there is a necessity of urgent performance of a surgery, the anticipated hemodynamic effect did not occur during $48 \mathrm{~h}$ of treatment. According to Ouriel [28] carrying out the fibrinolysis further in those cases can lead to the increase of incidence of haemorrhagic complications. From the clinically significant deterioration of the limb state, resulting from the persistent ischaemia, the passing deterioration of the peripheral parts of the limb, especially the foot, caused by the distal embolization with not entirely dissolved excerpts of thrombus needs to be distinguished. Galland et al. [47] consider that maybe it is permanent, but not always clinically visible, part of the thrombolytic treatment. The peripheral micro-embolization arises in a moment when the flow is restored in so far closed vessel. Usually small thrombi are dissolved when the thrombolytics infusion is continued. It has to be stressed that dissolution of the thrombus is the first stage of the treatment, and further procedure should aim at determining and removing the cause of the arterial occlusion. Patients who have been diagnosed with the arterial stenosis can be qualified for planned surgical treatment or to the therapy with transcutaneous endovascular techniques, preferably directly after the termination of thrombolysis and using the angioaccess created to carry out the thrombolysis. If the cause cannot be found by angiography, the intravascular ultrasound needs to 
be carried out. Lack of local cause of the occlusion or closing of the vessel caused by thrombus originating from higher located parts of the arteries or the heart cavities comprise indications to implement the long-term anti-coagulative treatment with low molecular weight heparin or oral anticoagulants. It can be also advisable to perform diagnostic procedures excluding the presence of clinical syndromes with hypercoagulability.

\section{Conclusions}

Local intravascular fibrinolysis is a good and effective method of treating the ischaemia of lower limbs in certain patients. It allows to significantly lower the thrombolytic drug dosage in comparison to the intravenous infusion, what leads to decreasing the incidence of complications. Careful determination of the indications and complying with the contraindications to apply fibrinolysis allows to obtain good results thanks to using the treatment less affecting the patient in comparison to the surgical treatment. Local fibrinolysis allows to shorten the hospitalisation and absence due to sickness time what is economically beneficial for the patient himself as well as for the clinic treating him.

\section{References}

I. Dotter CT, Rosch J, Seaman A (1974) Selective clot lysis with low-dose streptokinase. Radiology; I I I: 31-37.

2. Gianni D, Balbarini $A$ (2004) Thrombolytic therapyin peripheral arterial disease. Curr Drug Targets Cardiovasc Heamatol Disord; 4: 249-258.

3. Belkin M, Belkin B, Bucknam CA, Straub JJ, Lowe R (1986) Intra-arterial fibrinolytic therapy. Efficacy of streptokinase vs urokinase. Arch Surg; 121: 769-773.

4. Berridge DC, Gregson RH, Hopkinson BR, Makin GS (1991) Randomized trial of intra-arterial recombinant tissue plasminogen activator, intravenous recombinant tissue plasminogen activator and intra-arterial streptokinase in peripheral arterial thrombolysis. Br J Surg; 78: 988-995.

5. van Breda A, Katzen BT, Deutsch AS (1987) Urokinase versus streptokinase in local thrombolysis. Radiology; 165: 109-1II.

6. Cragg AH, Smith TP, Corson JD et al (199I) Two urokinase dose regimens in native arterial and graft occlusions: initial results of prospective randomized clinical trial. Radiology; 178: 68I-686.

7. Hess H, Mietaschk A, Bruckl R (1987) Peripheral arterial occlusions: a 6-year experience with local low-dose thrombolytic therapy. Radiology; 163: 753-758.

8. Huettl EA, Soulen MC (1995) Thrombolysis of lower extremity embolic occlusions: a study of the results of the STAR Registry. Radiology; 197: |41-145.

9. Kandarpa K, Chopra PS, Aruny JE et al (1993) Intra-arterial thrombolysis of lower extremity occlusions: prospective, randomized comparison of forced periodic infusion and conventional slow continuous infusion. Radiology; 188: 86I-867.

10. Kaufman JA, Bettmann MA (1992) Thrombolysis of peripheral vascular occlusions with urokinase. A review of the clinical literature. Seminars Int Radiol; 9: 159-165.
II. The STILE Investigators (1994) Results of a prospective randomized trial evaluating surgery versus thrombolysis for ischemia of the lower extremity. The STILE trial. Ann Surg; 220: 25I-268.

12. McNamara TO, Fisher JR (1985) Thrombolysis of peripheral arterial and graft occlusions: improved results using high-dose urokinase. AJR; I44: 769-775.

13. Meyerovitz MF, Goldhaber SZ, Reagan K et al (1990) Recombinant tissue-type plasminogen activator versus urokinase in peripheral arterial and graft occlusions: a randomized trial. Radiology; 175: 75-78.

14. Risius B, Graor RA, Geisinger MA, Zelch MG, Lucas FV, Young JE (1987) Thrombolytic therapy with recombinant human tissue-type plasminogen activator: a comparison of two doses. Radiology; 164: 465-468.

15. Lonsdale RJ, Berridge DC, Earnshaw JJ et al (1992) Recombinant tissue-type plasminogen activator is superior to streptokinase for local intra-arterial thrombolysis. Br J Surg; 79: 272-275.

16. Sullivan KL, Gardiner GA, Shapiro MJ, Bonn J, Levin DC (1989) Acceleration of thrombolysis with a high-dose transthrombus bolus technique. Radiology; 173: 805-808.

17. Berridge DC, Makin GS, Hopkinson BR (1989) Local low dose intra-arterial thrombolytic therapy: the risk of stroke or major haemorrhage. Br J Surg; 76: 1230-1233.

18. Browse DJ, Torrie EPH, Galland RB (1992) Low-dose intra-arterial thrombolysis in the treatment of occluded vascular grafts. Br J Surg; 79: 86-88.

19. Ouriel K, Shortell CK, DeWesse JA et al (1994) A comparison of thrombolytic therapy with operative revascularization in the initial treatment of acute peripheral arterial ischemia. J Vasc Surg; 19: 1021-1030.

20. Fogarty TJ, Cranley JJ (1965) Catheter technique for arterial embolectomy. Ann Surg; 161: 325-328.

21. Fogarty TJ (1966) Further experience with a new embolectomy catheter. Surgery; 59: 86-89.

22. Kostewicz W (1998) Hiperplazja naczyniowa jako odpowiedź na urazy i operacje naprawcze tętnicy. In: Noszczyk W (ed.) Chirurgia tętnic i żył obwodowych. PZWL, Warszawa, 100-108.

23. Schwarcz TH, Doberin PB, Mrkvicka R, Skowron L, Cole M (1988) Early myointimal hyperplasia after balloon catheter embolectomy: effect of shear forces and multiple withdrawals. J Vasc Surg; 7: 495-499.

24. Bowels CR, Olcott C, Pakter RL, Lombard C, Mehigan JT, Walter JF (1988) Diffuse arterial narrowing as a result of intimal proliferation: a delayed complication of embolectomy with the Fogarty catheter. J Vasc Surg; 7: 487-494.

25. Janosik JE, Bettmann MA, Kaul AF, Souney PF (199I) Therapeutic alternatives for subacute peripheral arterial occlusion: comparison by outcome, length of stay, and hospital charges. Ivest Radiol; 26: 921-925.

26. Berridge DC, Kessel DO, Robertson L et al. (2002) Surgery versus thrombolysis for initial management of acute limb ischaemia. Cochrane Database Syst Rev; 3: CD002784.

27. Braithwaite BD, Quinones-Baldrich WJ (1996) Lower limb intraarterial thrombolysis as an adjunct to the management of arterial and graft occlusions. World J Surg; 20: 649-654.

28. Ouriel K (200I) Peripheral arterial and bypass graft occlusion: thrombolytic therapy. In: Cameron JL (ed.) Current surgical therapy. Mosby, St. Louis, 943-948.

29. Marder VJ, Comerota AJ, Shlansky-Goldberg RD et al (2012) Safety of catheter-delivered plasmin in patients with acute low- 
er extremity arterial or bypass graft occlusion: phase I results. J Thromb Haemost; 10: 985-991.

30. Marder VJ, Landskroner K, Novokhatny V et al (200I) Plasmin induces local thrombolysis without causing hemorrhage: a comparison with tissue plasminogen activator in the rabbit. Thromb Haemost; 86: 739-745.

31. Stewart D, Kong M, Novokhatny V, Jesmok G, Marder VJ (2003) Distinct dose-dependent effects of plasmin and TPA on coagulation and hemorrhage. Blood; 101: 3002-3007.

32. Marder VJ (2008) Pre-clinical studies of plasmin: superior benefit-to-risk ratio of plasmin compared to tissue plasminogen activator. Thromb Res; 122 (suppl 3): S9-SI5.

33. Braithwaite BD, Quinones-Baldrich WJ (1996) Lower limb intraarterial thrombolysis as an adjunct to the management of arterial and graft occlusions. World J Surg; 20: 649-654.

34. Rabe F, Becker G, Richmond B (1982) Contrast extravasation through Dacron grafts. AJR; 138: 917-920.

35. Rosner NH, Doris PE (1984) Contrast extravasation through a Gore-Tex graft: a sequel of low-dose streptokinase therapy. AJR; 143: 633-634.

36. Hicks ME (1992) Delivery systems for various clinical applications in peripheral arterial thrombolysis. A practical approach. Seminars Interv Radiol; 9: 21 I-223.

37. Bookstein JJ, Valji K (1992) Pulse-spray pharmacomechanical thrombolysis. Cardiovasc Interv Radiol; 9: I74-182.

38. Bookstein JJ, Valji K (1992) Pulse spray pharmacomechanical thrombolysis. Updated clinical and laboratory observations. Seminars Interv Radiol; 9: 174-182.
39. Valji K, Bookstein JJ, Roberts AC, Sanchez RB (1993) Occluded peripheral arteries and bypass grafts: lytic stagnation as an end point for pulse-spray pharmacomechanical thrombolysis. Radiology; I88: 389-394.

40. Valji K, Roberts AC, Davis GB, Bookstein JJ (1991) Pulsed-spray thrombolysis of arterial and bypass graft occlusions. AJR; I56: 6|7-62|.

4I. Gardiner GA, Koltun W, Kandarpa K et al (1986) Thrombolysis of occluded femoropopliteal grafts. AJR; 147: 62I-626.

42. Conrad MF, Shepard AD, Rubinfeld IS et al (2003) Long-term results of catheter-directed thrombolysis to treat infrainguinal bypass graft occlusion: the urokinase era. J Vasc Surg; 37: 1009-1016.

43. Marder VJ, Comerota AJ, Shlansky-Goldberg RD et al (2012) Safety of catheter-delivered plasmin in patients with acute lower extremity arterial or bypass graft occlusion: phase I results. J Thromb Haemost; 10: 985-991.

44. A study of intra-thrombus plasmin (human) in acute peripheral arterial occlusion, last updated 20 June 20II. NCTOI222II7. Clinical Trials.

45. Wissgott C, Richter A, Kamusella P, Steinkamp HJ (2007) Treatment of critical limb ischaemia using ultrasound-enhanced thrombolysis (PARES Trial): final results. J Endovasc Ther; 14: 438-443.

46. Kandarpa K (1994) Intra-arterial thrombolysis. Wykład. Sesja Warszawskiego Oddziału TCHU, 17.06.1994, Warszawa.

47. Galland RB, Earnshaw JJ, Baird RN et al (1993) Acute limb deterioration during intra-arterial thrombolysis. $\mathrm{Br}$ J Surg; 80: III8-II 20. 